Research Paper

\title{
Comparative proteomic analysis of trypomastigotes from Trypanosoma cruzi strains with different pathogenicity
}

\author{
Alfonso Herreros-Cabello ${ }^{\mathrm{a}}$, Francisco Callejas-Hernández ${ }^{\mathrm{a}}$, Manuel Fresno ${ }^{\mathrm{a}, \mathrm{b}, *}$, Núria Gironès ${ }^{\mathrm{a}, \mathrm{b}, *}$ \\ ${ }^{a}$ Centro de Biología Molecular Severo Ochoa, Consejo Superior de Investigaciones Científicas, Universidad Autónoma de Madrid, Cantoblanco, Madrid, Spain \\ ${ }^{\mathrm{b}}$ Instituto Sanitario de Investigación la Princesa, Madrid, Spain
}

\section{A R T I C L E I N F O}

\section{Keywords:}

Trypanosoma cruzi

Chagas disease

Trypomastigote

Proteome

Gene ontology

Enriched metabolic pathways

\begin{abstract}
A B S T R A C T
Chagas disease, caused by the parasite Trypanosoma cruzi, is one of the most neglected diseases in Latin America, being currently a global health problem. Its immunopathogenesis is still quite unknown. Moreover, there are important differences in pathogenicity between some different $T$. cruzi strains. For example, in mice, $\mathrm{Y}$ strain produces a high acute lethality while VFRA remains in the host mostly in a chronic manner.

Comparative proteomic studies between $T$. cruzi strains represent a complement for transcriptomics and may allow the detection of relevant factors or distinctive functions. Here for the first time, we compared the proteome of trypomastigotes from 2 strains, Y and VFRA, analyzed by mass spectrometry. Gene ontology analysis were used to display similarities or differences in cellular components, biological processes and molecular functions. Also, we performed metabolic pathways enrichment analysis to detect the most relevant pathways in each strain.

Although in general they have similar profiles in the different ontology groups, there were some particular interesting differences. Moreover, there were around 10\% of different proteins between Y and VFRA strains, that were shared by other T. cruzi strains or protozoan species. They displayed many common enriched metabolic pathways but some others were uniquely enriched in one strain. Thus, we detected enriched antioxidant defenses in VFRA that could correlate with its ability to induce a chronic infection in mice controlling ROS production, while the Y strain revealed a great enrichment of pathways related with nucleotides and protein production, that could fit with its high parasite replication and lethality. In summary, Y and VFRA strains displayed comparable proteomes with some particular distinctions that could contribute to understand their different biological behaviors.
\end{abstract}

\section{Introduction}

Trypanosoma cruzi is the etiological agent of Chagas disease or American Trypanosomiasis, a chronic endemic illness of Latin America, and a neglected tropical disease (World Health Organization Chagas disease (American trypanosomiasis), 2019). In endemic areas, vectorial transmission is the most common way to get infected, while blood and organ transplantation transmission are becoming a health problem in some non-endemic countries due to immigration (Bern et al., 2007; Schmunis and Yadon, 2010). Nowadays, it has been estimated that there are around 6-7 million of chronically infected people (World Health Organization Chagas disease (American trypanosomiasis), 2019).

T. cruzi life cycle is very complex, involving an invertebrate hematophagous triatomine as principal vector (Clayton, 2010). In the digestive tract of triatomines they have the non-infective epimastigotes and in the final portion of the intestine the infective metacyclic trypomastigotes. Infection of mammals occurs when they come into contact with the infective metacyclic forms of the parasite that are eliminated with the feces of triatomines. After the infection of host cells $T$. cruzi differentiates to the intracellular replicative amastigotes, that after several rounds of intracellular replication they lyse the cell and escape as bloodstream trypomastigotes and the cycle continues (de Souza et al., 2010; De Souza, 2002; Rodrigues et al., 2014). Chagas disease presents three clinical phases (Rassi Jr. et al., 2012). Acute phase with low mortality and symptomatology, asymptomatic chronic phase for years or for life, and clinical chronic phase in which $30-40 \%$ of the patients will present after 10-30 years a chronic myocarditis, megavisceras or both. Nowadays, there are only two drugs (Nifurtimox and Benznidazole) with questioned efficacy in chronically infected adults

\footnotetext{
* Corresponding authors at: Centro de Biología Molecular Severo Ochoa, Consejo Superior de Investigaciones Científicas, Universidad Autónoma de Madrid, Cantoblanco, Madrid, Spain.

E-mail addresses: mfresno@cbm.csic.es (M. Fresno), ngirones@cbm.csic.es (N. Gironès).
} 
and having many adverse effects (Bermudez et al., 2016; Muller Kratz et al., 2018; Sales Junior et al., 2017).

T. cruzi presents a huge genomic variability (Reis-Cunha et al., 2015; Callejas-Hernandez et al., 2018), and 6 different "discrete typing units" (DTU) named from TcI to TcVI (Zingales et al., 2009) have been described. This classification has been established based on some conserved genetic sequences (genomic and mitochondrial DNA). A potential seventh DTU (Tcbat) (Marcili et al., 2009; Zingales et al., 2012) was described in bats and with subsequent studies based on diverse molecular markers it has been described as a seventh DTU (Lima et al., 2015). It has been proposed that both the parasite and host genetic variability may be the causes of differential clinical manifestations of the disease (Zingales et al., 2012), (Manoel-Caetano Fda and Silva, 2007). The parasite can invade many nucleated cells of the human body, although it infects more frequently macrophages, dendritic cells (DCs) and cardiomyocytes (Campbell et al., 2004; Teixeira et al., 2006; Gil-Jaramillo et al., 2016).

T. cruzi strains highly differ in pathogenicity. Some are acute lethal strains as $\mathrm{Y}$, whereas others, such as VFRA, produce a chronic infection in BALB/c mice (Rodriguez et al., 2014). Mice infected with Y strain die after 30 days, while the mice infected with VFRA survive for months. Furthermore, Y strain produces higher levels of parasitemia and more replication rates in macrophages and heart than VFRA strain.

Transcriptomic and proteomics studies have been performed to understand the changes at a molecular level that could explain the differences that are observed in the infection models. There are proteomes of different $T$. cruzi strains available in the public databases. However, most of these proteomes are product of in silico genome translations. Only a few publications about $T$. cruzi proteomes were studied by mass spectrometry and most of them comparing different parasite stages (Atwood 3rd et al., 2005; Avila et al., 2018; BayerSantos et al., 2013; de Godoy et al., 2012; Brunoro et al., 2015; Ribeiro et al., 2018; Queiroz et al., 2013). One of the first studies analyzed the different life-cycle stages of CL-Brener strain (Atwood 3rd et al., 2005), showing apparently distinct energy sources between them, as carbohydrates and lipids for trypomastigotes and amastigotes forms, or histidine in the insect vector. The proteomes of metacyclogenesis in Dm28c epimastigotes has also been performed to determine how the expression of specific proteins change in this process (de Godoy et al., 2012). Other researchers focused on specific forms of the parasite such as the CL-Brener epimastigotes in the exponential and stationary growth phases (Avila et al., 2018), showing a regulation of proteins involved in different subcellular compartments or metabolic pathways such as glycolysis, whereas others focused on establishment of the bloodstream trypomastigotes proteome of $\mathrm{Y}$ strain (Brunoro et al., 2015). Not only total proteomes have been established, specific cell surface proteome of the parasite has been previously analyzed, adding new previously undetected proteins to the parasite proteomes (Queiroz et al., 2013). Also, the secretome of extracellular vesicles of different strains have been studied (Bayer-Santos et al., 2013; Ribeiro et al., 2018) supporting the notion that T. cruzi uses different secretion pathways to excrete/secrete particular proteins. However, comparisons between strains have not been performed extensively and this should allow discovering strain-specific differences that could explain their distinctions in their pathogenicity.

In this work, we focused for the first time on the comparative analysis between trypomastigote proteomes of Y and VFRA strains, because of their different immunopathogenic behavior in mice (Rodriguez et al., 2014). We performed gene ontology and metabolic pathway enrichment analysis to understand in a global way the principal functions, processes or pathways that are representative of each strain.

\section{Materials and methods}

\subsection{Parasite culture and isolation}

Y T. cruzi strain was obtained from Dr. David (Harvard Medical School, Boston, MA, USA) and VFRA strain from ChagasEpiNet VII Framework Consortium. Vero cells (African green monkey kidney, ATCC) were grown in RPMI medium supplemented with $5 \%$ fetal bovine serum (FBS), $100 \mathrm{UI} / \mathrm{mL}$ of antibiotics mixture, $10 \mu \mathrm{g} / \mathrm{mL}$ streptomycin (Streptomycin Sulfate BioChemica, PanReac AppliChem) and $2 \mathrm{mM}$ L-glutamine (Merck) at $37^{\circ} \mathrm{C}$ in an atmosphere of $5 \% \mathrm{CO}_{2}$ until the cells reached $80 \%$ confluence. The cell monolayer was subsequently infected with metacyclic trypomastigotes (VFRA and Y, 10 parasites per cell). After 4 days, the supernatant medium was collected. Trypomastigotes were obtained from these Vero cell co-cultures by differential centrifugation at $1000 \mathrm{~g}$ for $5 \mathrm{~min}$ to eliminate the amastigotes and dead cells and centrifugation at $1600 \mathrm{~g}$ for $10 \mathrm{~min}$ to isolate them.

\subsection{Protein extraction and digestion}

Parasites were lysed in lysis buffer (50 mM Tris-HCl pH 7.5, $150 \mathrm{mM}$ $\mathrm{NaCl}, 2 \mathrm{mM}$ EDTA, $1 \mathrm{mM}$ EGTA, $1 \%$ Triton X-100) in the presence of protease (Complete tablets Easypack, Roche) and phosphatase inhibitors (PhosSTOP, Roche) following the provider's instructions. In the case of protease inhibitors, a double amount was used due to the high rate of expression of proteases by the parasites. Protein concentrations were determined by the Bicinchoninic acid assay (BCA Protein Assay, Thermo Scientific) using an extrapolation on a standard curve of known concentrations of Bovine Serum Albumin (BSA). Then, a 1D-gel containing $500 \mu \mathrm{g}$ of each sample was run to concentrate proteins and stained with the Colloidal Blue Staining Kit (Invitrogen) for protein visualization. We obtained a high protein concentration, therefore the spots of maximum protein concentration were automatically excised using a ProteomeWorks Spot Cutter (Bio-Rad), separated in smaller fractions and subjected to manual tryptic digestion (Cristobo et al., 2011). Destaining of the gel pieces was done first with $50 \mathrm{mM}$ ammonium bicarbonate (Sigma-Aldrich) and second with acetonitrile (ACN) (Scharlau). Proteins were reduced with $10 \mathrm{mM}$ dithiothreitol (SigmaAldrich) at $56^{\circ} \mathrm{C}$ for $30 \mathrm{~min}$. Prior to digestion, proteins were alkylated replacing the previous solution with $40 \mathrm{mM}$ iodoacetamide (Sigma-Aldrich) and incubating at room temperature for $60 \mathrm{~min}$ in the dark. For the digestion, $12.5 \mathrm{ng} / \mu \mathrm{L}$ of trypsin (Promega) in $50 \mathrm{mM}$ ammonium bicarbonate solution was added to the gel pieces for $8 \mathrm{~h}$ at $37^{\circ} \mathrm{C}$. Finally, peptide extraction was performed adding 70\% ACN containing $0.5 \%$ trifluoroacetic acid (TFA) (Sigma-Aldrich). Tryptic eluted peptides were dried by speed-vacuum centrifugation and resuspended in $4 \mu \mathrm{L}$ of $30 \% \mathrm{ACN}-0.1 \%$ TFA. One $\mu \mathrm{L}$ of each peptide mixture was deposited onto an $800 \mu \mathrm{m}$ AnchorChip (Bruker-Daltonics) and dried at room temperature. One $\mu \mathrm{L}$ of matrix solution $(3 \mathrm{mg} / \mathrm{mL} \alpha$-cyano-4-hydroxycinnamic acid) in $33 \%$ ACN $-0.1 \%$ TFA was deposited onto the digest and allowed to dry at room temperature. Two biological replicates and two technical replicates were acquired for each condition.

\subsection{NanoLC-MS/MS analysis and protein identification}

Samples were analyzed using an EASY-nano LC system (Proxeon Biosystems) coupled online with an LTQ-Orbitrap Velos mass spectrometer (Thermo Scientific). For the chromatographic separation, after the retention in a precolumn Acclaim PepMap 100 (Thermo Scientific), peptides were eluted in a column Acclaim PepMap 100 C18, with $25 \mathrm{~cm}$ of length, $75 \mu \mathrm{m}$ of inner diameter and $3 \mu \mathrm{m}$ of particle size (Thermo Scientific). Peptides mixtures were separated using a gradient from phase A $(0,1 \%$ formic acid) to $35 \%$ phase B $(0,1 \%$ formic acid in acetonitrile) for $100 \mathrm{~min}, 35 \%$ to $45 \%$ phase B for $20 \mathrm{~min}$; $45 \%$ to $95 \%$ phase B for $5 \mathrm{~min}, 95 \%$ phase B for $4 \mathrm{~min}$ and $0 \%$ phase B for $1 \mathrm{~min}$. A 
Table 1

Summary of the number of unique, shared and hypothetical proteins detected in the mass spectrometry in each strain.

\begin{tabular}{|c|c|c|c|c|c|}
\hline Strain & Total proteins detected & Hypothetical proteins & Total proteins shared & Total unique proteins & Unique proteins with detected function \\
\hline $\mathrm{Y}$ & 2117 & 879 & 1820 & 297 & 57 \\
\hline VFRA & 1983 & 749 & 1820 & 163 & 57 \\
\hline
\end{tabular}

total of $130 \mathrm{~min}$ with a flow rate of $250 \mathrm{~nL} / \mathrm{min}$.

Mass spectra were acquired in positive ion mode by applying a datadependent automatic survey MS scan and tandem mass spectra (MS/ MS) acquisition mode. Survey full-scan MS spectra (with a range of $300-1800 \mathrm{~m} / \mathrm{z}$ and a resolution of $R=60,000$ at $\mathrm{m} / \mathrm{z}=400$ ) were acquired in the Orbitrap analyzer. After that the 15 most intense ions were sequentially isolated and fragmented in the LTQ using collisioninduced dissociation (CID) with a normalized collision energy of $35 \%$. Selected sequenced ions were dynamically excluded for $45 \mathrm{~s}$.

Raw files were searched against a protozoan database of UniProt (downloaded in August 2018) that contained some of the most representative and studied strains of T. cruzi such as CL-Brener, Dm28c, Sylvio X10 and Marinkellei and other related species as Leishmania and Trypanosoma brucei among others, using Proteome Discoverer (Version 1.4.1.14, Thermo Scientific) with Sequest algorithm. Carbamidomethylation of cysteines and oxidation of methionines were set as fixed modifications. Search parameters specified a MS tolerance of $7 \mathrm{ppm}$ and a MS/MS tolerance of 0,5 Da. Peptide identification was validated by the algorithm Percolator using a $\mathrm{q} \leq 0,01$ (Kall et al., 2007) and a minimum peptide length of six amino acids residues.

\subsection{Data analysis}

Proteins were classified by gene ontology (GO) analysis using Blast2GO software (Conesa et al., 2005). This tool uses basic local alignment search tool (BLAST) and InterPro algorithms to associate possible functions to our detected sequences. Then, the software classifies the functions along the first three levels of ontology: biological processes, cellular components and molecular functions identifying the proteins that belong to each level. BLAST analyses against different $T$. cruzi databases of the unique proteins in each strain were performed with the available tool in the website https://blast.ncbi.nlm.nih.gov/ Blast.cgi establishing a filter of $>90 \%$ similarity to consider two proteins as the same protein. For the metabolic pathway enrichment analysis, we used the TriTrypDB website tools (https://tritrypdb.org/ tritrypdb/) that perform a Fisher's exact test to determine the significant pathways with a $p$-value adjusted using the Benjamini-Hochberg $(\mathrm{BH})$ method to control FDR. Only pathways with FDR equal or lower than 0.05 were displayed. Venn diagrams were done with the tool of the Bioinformatics \& Evolutionary Genomics (http://bioinformatics. psb.ugent.be/webtools/Venn/). All the other figures were done using R program (Version 3.5.1).

\subsection{Repository data}

The mass spectrometry proteomics data have been deposited to the ProteomeXchange Consortium (Deutsch et al., 2017) via the PRIDE (Perez-Riverol et al., 2019) partner repository with the dataset identifier PXD012536.

\section{Results and discussion}

\subsection{Proteomes of trypomastigotes from $Y$ and VFRA T. cruzi strains}

We analyzed trypomastigote proteomes by mass spectrometry. For protein identification from peptide sequences we used a non-redundant protozoan protein database from UniProt. We detected 6759 different peptides in the Y strain and 6957 in the VFRA strain. Those peptides can be ascribed to a total of 2117 proteins in Y strain and 1983 in VFRA strain (Supplementary Table 1). Since most of the T. cruzi proteins deduced from the genome correspond to hypothetical proteins of unknown function (Callejas-Hernandez et al., 2018) is not surprising that in our proteomes there were 879 hypothetical proteins in Y strain and 749 in VFRA strain (Table 1). We performed BLAST analysis between the detected proteins in both proteomes, establishing a threshold in $>90 \%$ of similarity to suppose that two proteins are the same. According to this, from the 2117 proteins detected in the $\mathrm{Y}$ strain proteome and the 1983 proteins of the VFRA strain proteome, 1820 proteins were shared by both strains. Therefore, about $90 \%$ of proteins are common by both strains and they have around $10 \%$ of unique proteins that could correlate with particular functions or processes of each strain. Interestingly, among the unique proteins 240 proteins in $Y$ strain and 106 in VFRA are hypothetical, and each strain has only 57 unique proteins with a known-function.

\subsection{Comparison of trypomastigote proteomes of $Y$ and VFRA strains}

With the detected proteomes, a gene ontology (GO) analysis was performed for each strain by the Blast2GO software, that gives a hierarchical classification in levels that summarizes the most common ontology groups of the original dataset. We compared the results between strains in the different ontologies through the principal levels that refer to the most relevant and global processes of the parasite.

\subsubsection{Cellular components}

In the level 2, the immediate level after the assignment of proteins to each ontology, there were about 300 proteins in the cell and cell part groups in both strains, a bit more in Y strain (Fig. 1). Furthermore, there were about 150 proteins in the membrane, membrane part, organelle and protein-containing groups. Y strain displayed a bit more proteins in organelle group, while VFRA presented more proteins in membrane and membrane part groups. According to GO Consortium terminology, cell part refers to any constituent part of the cell, and cell includes the same plus the plasma membrane and external encapsulating structures. The same applied to other groups such as membrane and membrane part, in this one we have any constituent of a membrane, and in membrane we include any protein embedded or attached to it.

Then, we analyzed deeper some of the more relevant groups in the level 2 attending to the number of proteins and type of sub-groups in the following third and fourth levels. Sub-groups that represent specific components of the cell can be visualized in Fig. 2A for Y strain and 2B for VFRA strain (complete data is shown in Supplementary Fig. S1). Inside the cell part group, we found some groups with more members in VFRA than Y strain, such as cell projection and envelope, with around 15 proteins. Respect to the endomembrane system subgroup, there was a higher number in $\mathrm{Y}$ strain, with $>25$ proteins.

In both strains, there were a lot of intracellular organelles proteins, but more in Y strain ( $>175$ proteins). Also, inside the group of proteincontaining complex $\mathrm{Y}$ strain displayed more proteins for the ribonucleoprotein and DNA packaging complexes than VFRA strain. All together suggest that $\mathrm{Y}$ strain possess more proteins dedicated to replication, which fits with the higher replication and proliferation of this strain comparing to VFRA (Rodriguez et al., 2014). Moreover, in the membrane group both strains displayed $>125$ intrinsic components of membrane, that correlates with other previous proteome studies of other strains and forms of T. cruzi (Avila et al., 2018; Brunoro et al., 


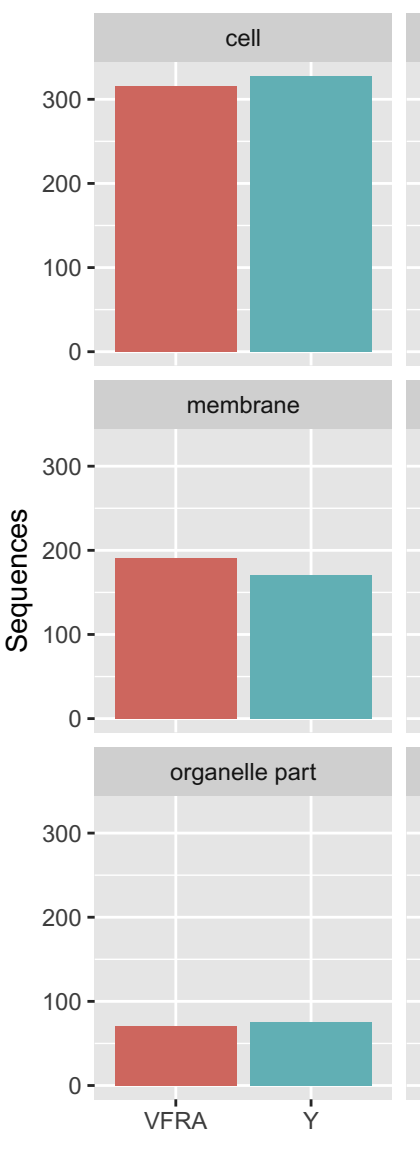

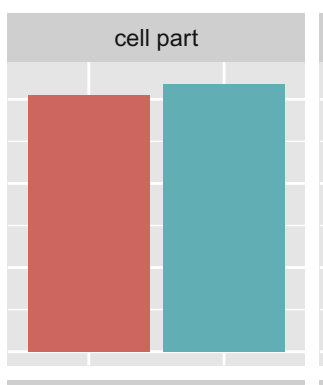
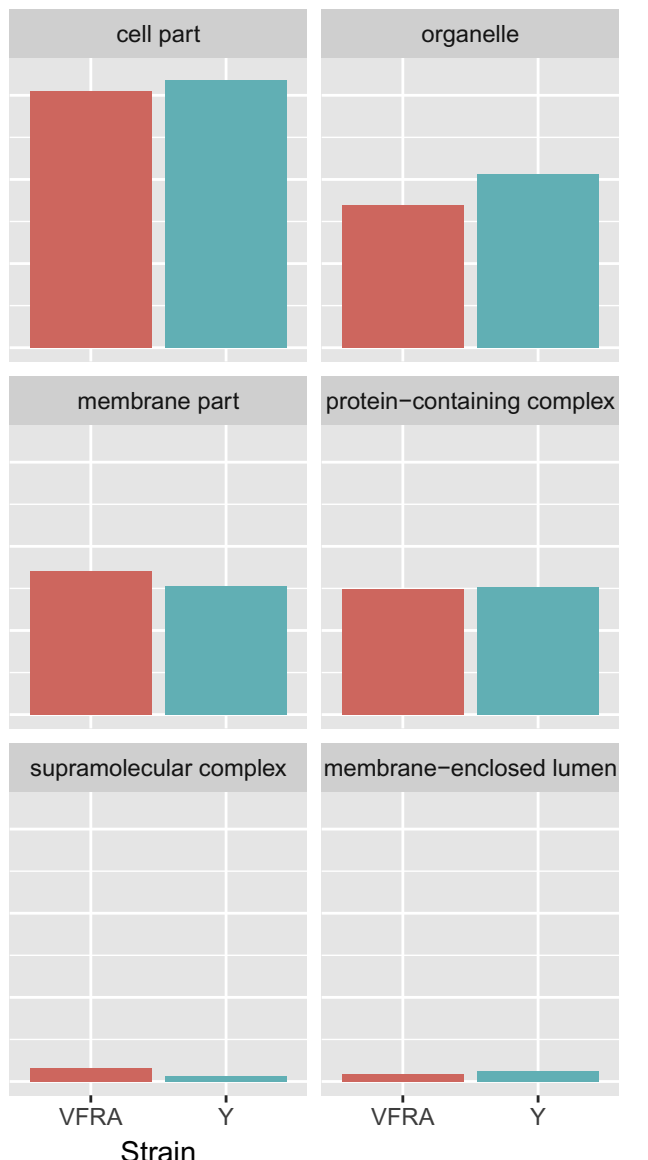
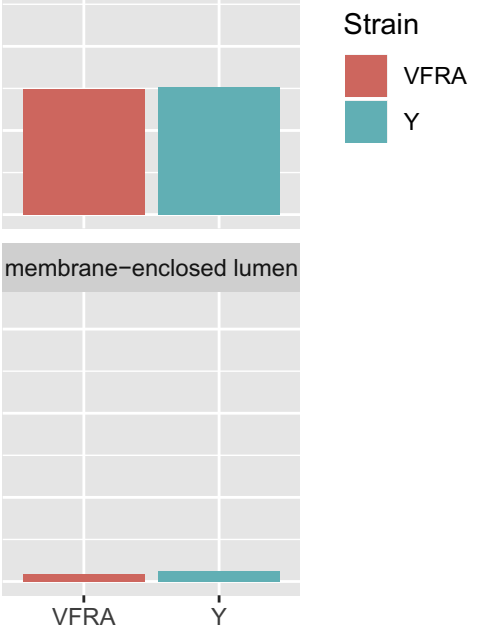

Fig. 1. Level 2 of cellular components. Gene ontology enrichments obtained from the Blast2GO software, classified by sequences and ontology groups.

2015), supporting the relevance of the membrane proteins for this parasite. Interestingly, we have detected more proteins that belong to photosynthetic complexes in VFRA than in Y strain. Photosynthetic processes in trypanosomes are mostly unknown, but some authors have discovered genes with photosynthetic potential (Hannaert et al., 2003) and functions of algae or plants in protists as Leishmania major or T. cruzi (Mulangi et al., 2012; Teich et al., 2007).

\subsubsection{Biological processes}

Level 2 groups with more members were metabolic and cellular processes with $>400$ proteins followed by localization group with around 80 proteins in both strains (Fig. 3). In those, together with biological regulation and multi-organism process groups, VFRA showed a bit more proteins than Y strain, while in the case of biogenesis, detoxification and response to stimulus groups a bit more members were displayed in $\mathrm{Y}$ than VFRA strain. However, there were not critical differences in the number of proteins between both strains. Therefore, generally we can say that these parasites have similar profiles.

Regarding the third and fourth levels for Y (Fig. 4A) and VFRA strain (Fig. 4B), in metabolic process, the most represented sub-groups were organic substance, primary, cellular and nitrogen compound metabolism with $>300$ proteins. Metabolic process is one of the biological processes with more detected proteins in the previously described proteomes of different strains and forms of the parasite (Avila et al., 2018; Brunoro et al., 2015). Considering the cellular processes, we found some relevant sub-groups such as cellular component organization and microtubule-based process with a bit more members in VFRA strain, and others such as protein folding with a bit more members in $\mathrm{Y}$ strain. These particular sub-groups, together with response to stress, have been detected in previous transcriptomic studies as common high expressed genes in trypomastigotes (Berna et al., 2017), and our results confirms their expression in a protein level enhancing their relevance for the parasite. Also, some of the differences that we found in the level 2 can be found again, as more proteins in the sub-groups of metabolic processes in VFRA strain. Globally, both strains display similar profiles considering the biological process ontology (Supplementary Fig. S2).

\subsubsection{Molecular functions}

In upper level 2 analysis, we found two groups with $>400$ sequences: binding and catalytic activity in both strains (Fig. 5), and in both VFRA displayed more proteins than Y strain, being more evident in the case of catalytic activity. Those high numbers likely indicate the need of proteins/enzymes required for a large number of processes and functions. VFRA displayed a bit more proteins for transporter activity and in the case of structural molecule and antioxidant activity there were more proteins in Y than VFRA strain, although the differences were minimal.

In the analysis of the third and fourth levels (Fig. 6), there were no big differences between strains in the sub-groups of binding or catalytic activity, although a bit more proteins in the case of VFRA strain subgroups was observed, which correlates with the previous analysis of the level 2. Interestingly, the sub-group of drug binding has proteins that interact with drug compounds that are used for diagnosis, prevention or treatment, although the final effect of the interaction cannot be inferred. Interestingly, both strains displayed $>100$ proteins with this molecular function that has not been detected in other gene ontology studies of epimastigotes of Dm28c (de Godoy et al., 2012) and CLBrener strains (Avila et al., 2018), suggesting their relevance for the infective trypomastigote form of the parasite. They include many proteasome proteins or ubiquitin enzymes that are being assessed as new drug targets (Gupta et al., 2018), or proteins for the export of drugs as different ABC transporters (da Costa et al., 2018; Zingales et al., 2015), in line with the available information about the drug resistance of $T$. 

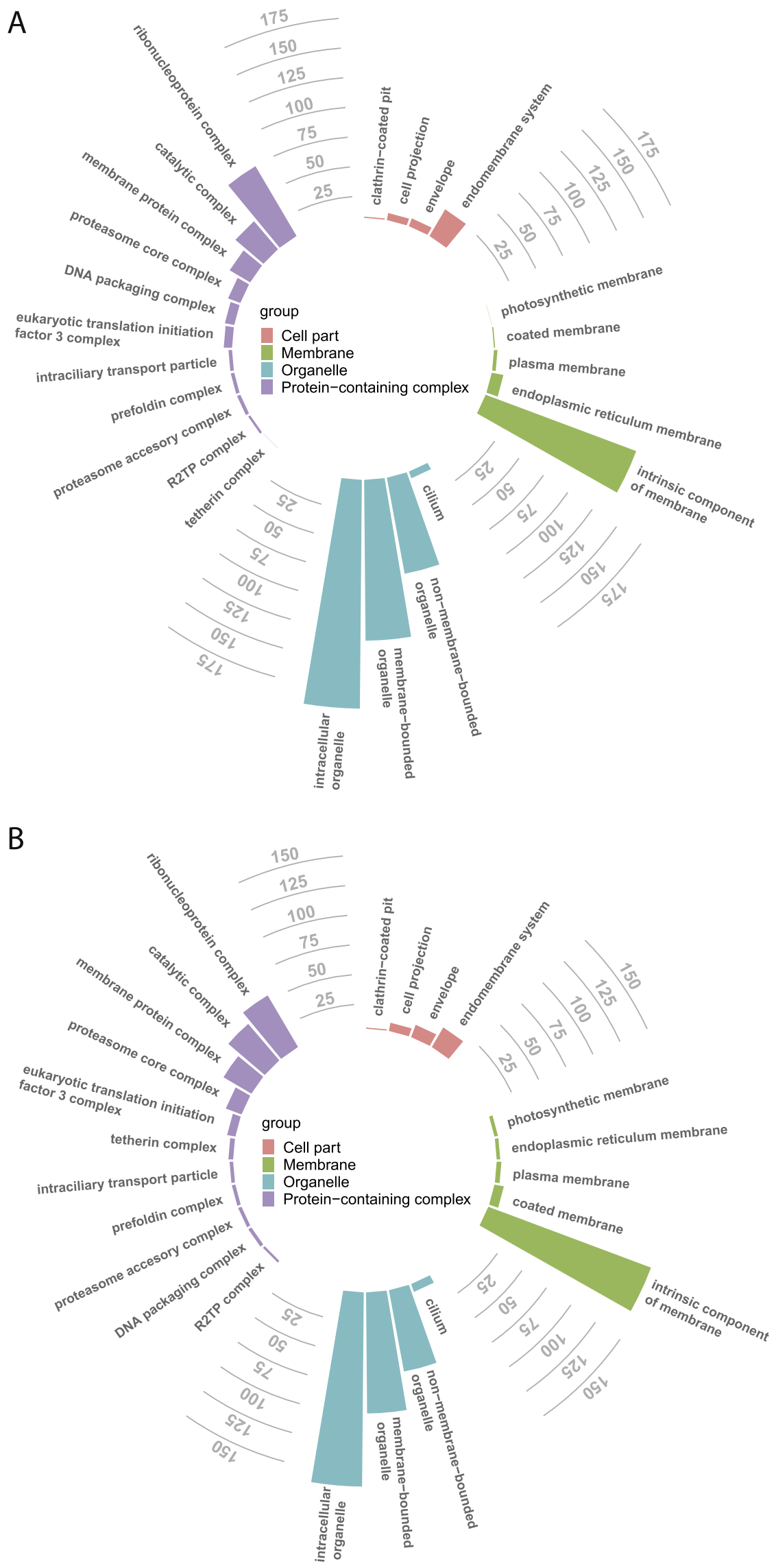

Fig. 2. Levels 3 and 4 of cellular components. Number of proteins in the sub-groups (levels 3 and 4 in the Blast2GO analysis) of the principal groups (level 2) in the cellular components ontology. (A) Classification for Y strain. (B) Classification for VFRA strain. 

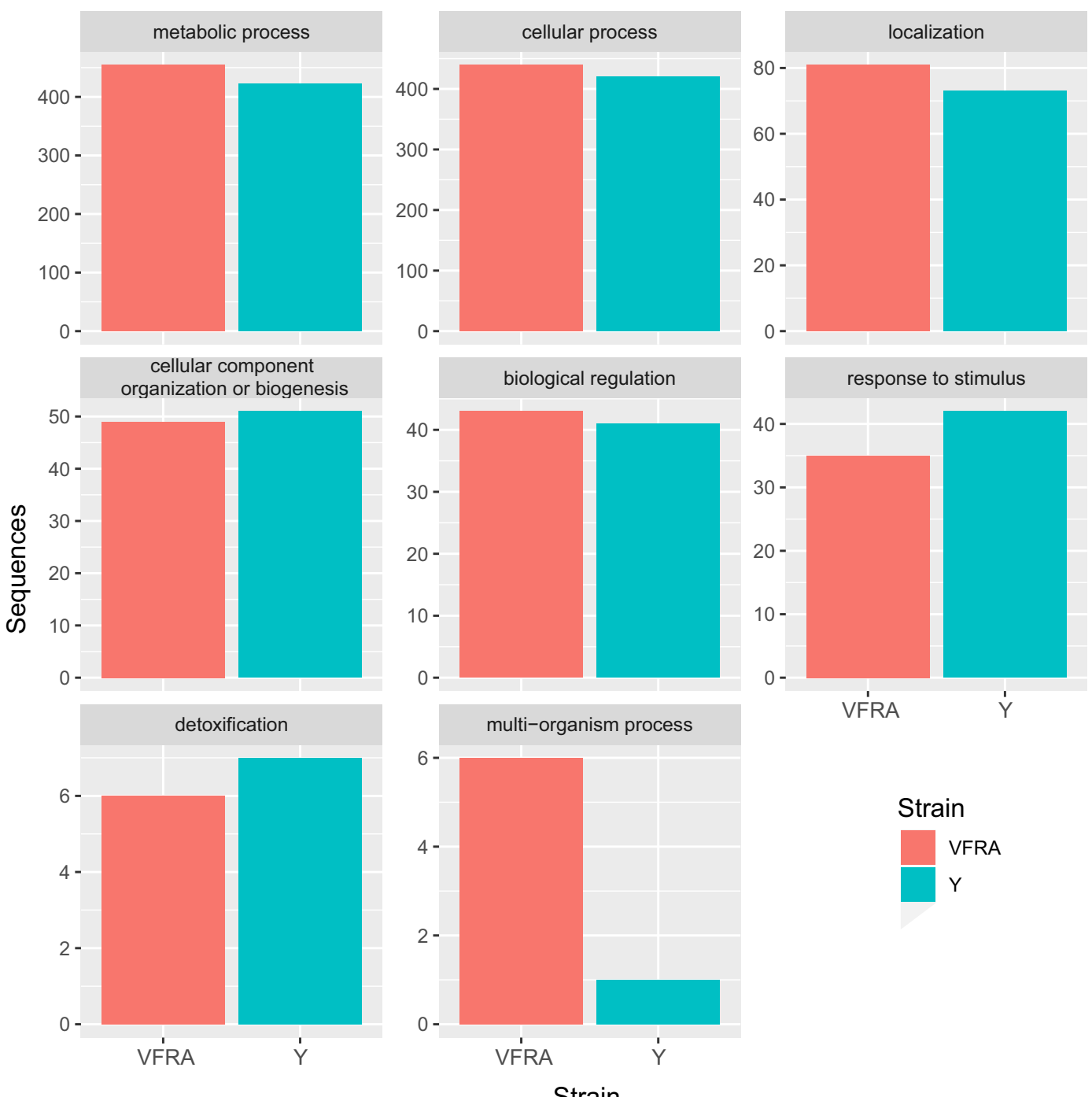

Fig. 3. Level 2 of biological processes. Gene ontology enrichments obtained from the Blast2GO software, classified by sequences and ontology groups.

cruzi (Zingales, 2018).

In the structural molecule group, the subgroup of structural constituent of the ribosome displayed more members ( $>50$ ) in the case of Y strain, supporting the idea about a better proliferation and protein production of Y strain respect to VFRA strain (Rodriguez et al., 2014). In the other groups, the differences among strains were scarce. Therefore, despite some punctual differences, in the principal levels of molecular functions ontology both strains display very close profiles (Supplementary Fig. S3).

Considering all the ontology aspects of the GO analysis, Y and VFRA strains show comparable compositions. The very similar results in biological processes and molecular functions represents a logical effect because they contain critical proteins for the cellular maintenance and anabolic/catabolic metabolism. However, there were a few differences that could be strain-specific pointing to differences in biological behavior.

\subsubsection{Unique proteins of each strain proteome}

Around a $10 \%$ of the total identified proteins were unique in each strain: 297 proteins in Y strain that were not found in VFRA strain and 163 proteins in VFRA strain that were not found in Y strain. However, a lot of them were hypothetical, 240 in Y and 106 in VFRA. Therefore, each strain only displayed 57 unique proteins with known-function.

Then, we searched by BLAST the unique proteins in other $T$. cruzi strains to detect if there are groups of strains with those proteins. We used different in silico proteome databases obtained from the previous genome assemblies of the following strains: Dm28c (Grisard et al., 2014; Berna et al., 2018), Sylvio X10 (Franzen et al., 2011), CL-Brener Non-Esmeraldo-like (El-Sayed et al., 2005) and CL-Brener Esmeraldolike (El-Sayed et al., 2005). We downloaded the databases from the Tritrypdb website (https://tritrypdb.org/tritrypdb/).Regarding the 57 Y strain unique proteins, we obtained 42 proteins with more than a $90 \%$ of similarity in other $T$. cruzi strains. Inside this group, 41 were detected in Dm28c, 40 in CL-Brener Non-Esmeraldo-like, 36 in CL-Brener Esmeraldo-like and 20 in Sylvio X10. In the case of the 57 VFRA strain unique proteins there were 40 proteins with that similarity in other $T$. cruzi strains, 39 were detected in Dm28c, 38 in CL-Brener Non-Esmeraldo-like, 30 in CL-Brener Esmeraldo-like and 15 in Sylvio X10.

The remaining 15 unique proteins of Y strain and 17 of VFRA strain, that did not have a similar protein in other T. cruzi strains have, however, counterparts in other protozoan species. Those results are summarized in a Venn diagram to display the proteins shared with strain $\mathrm{Y}$ (Fig. 7A) or VFRA strain (Fig. 7B). In conclusion, our proteome analyses have showed small number of proteins not present in all strains of $T$. cruzi, with some overlapping among strains, whereas others apparently unique of $Y$ or VFRA strains are shared with different protozoan species. 

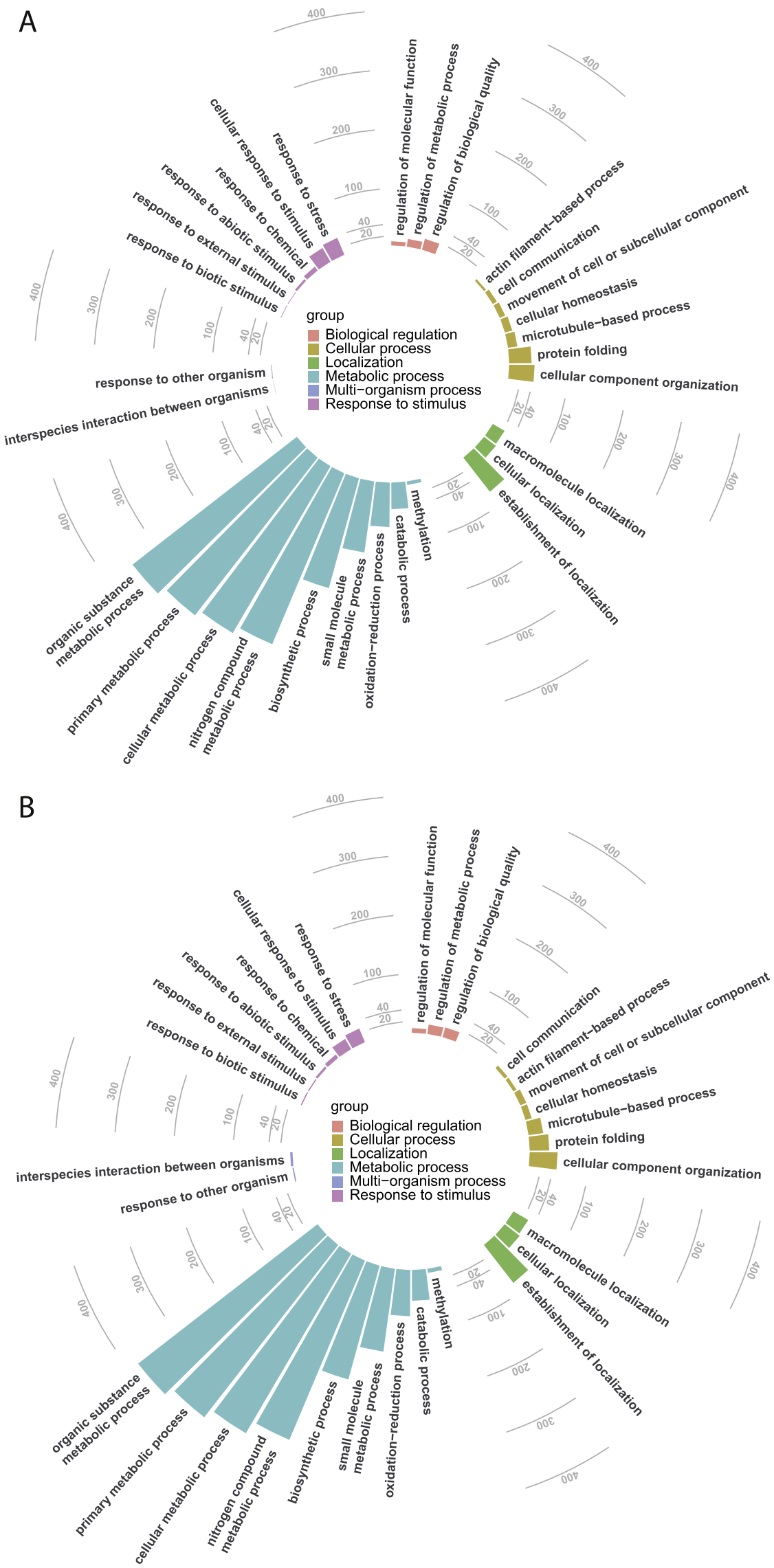

Fig. 4. Levels 3 and 4 of biological processes. Number of proteins in the sub-groups (levels 3 and 4 in the Blast2GO analysis) of the principal groups (level 2) in the biological processes ontology. (A) Classification for Y strain. (B) Classification for VFRA strain. 


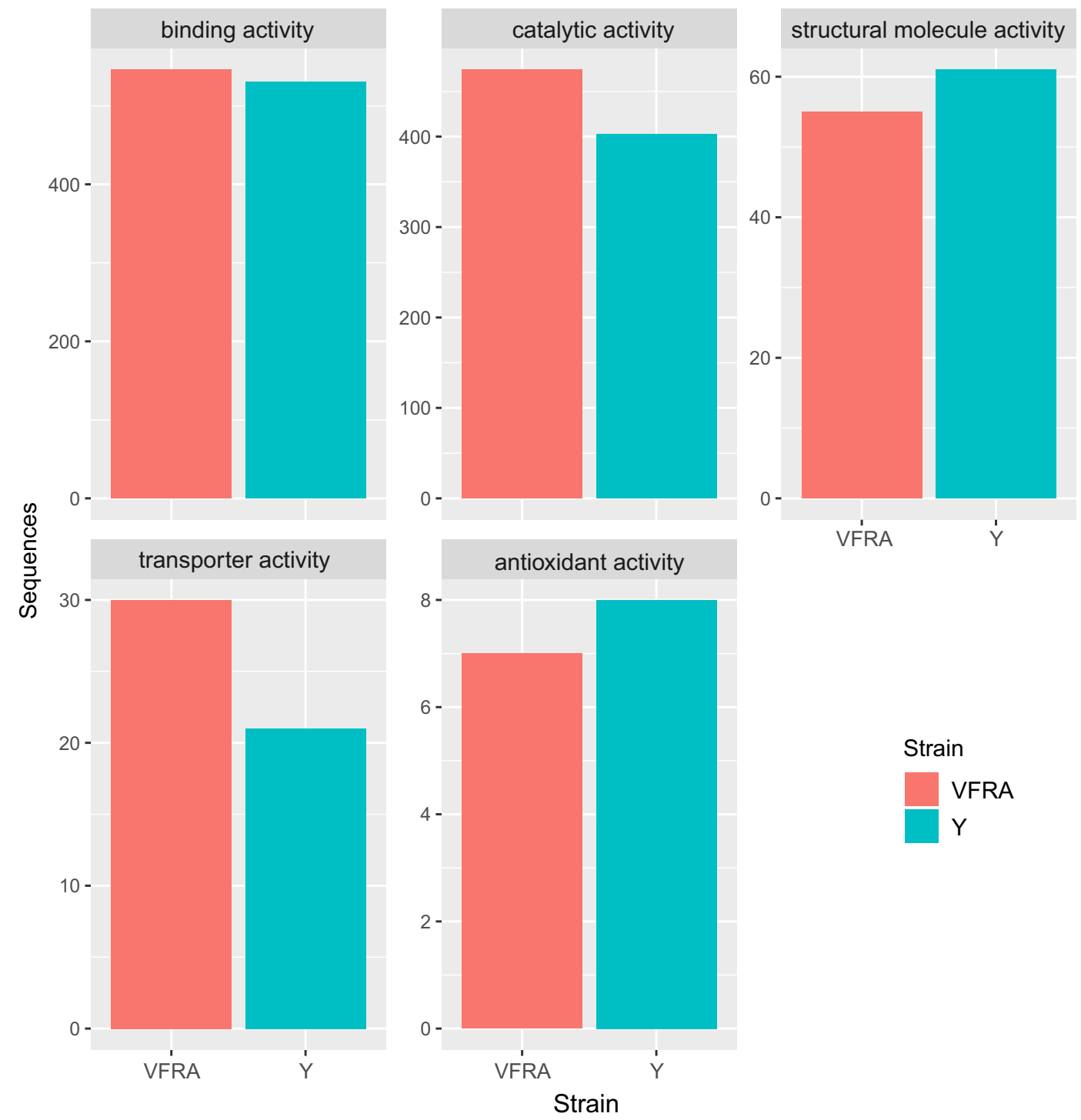

Fig. 5. Level 2 of molecular functions. Gene ontology enrichments obtained from the Blast2GO software, classified by sequences and ontology groups.

\subsection{Metabolic pathway enrichment analysis displays differences between $Y$ and VFRA T. cruzi strains}

Metabolic pathway enrichment tool performs a Fisher's exact test to analyze the enrichment or significance of typical pathways in our data set. We found many similarities, but interestingly, critical differences in some aspects among strains. The majority of shared enriched metabolic pathways (Fig. 8A) were related with: a) the replication and growth of the parasite as different pathways of nitrogen bases or amino acids biosynthesis, and b) energy production as variations of the TCA cycle and the succinate/acetate metabolism, Acetyl-CoA metabolism or the glyoxylate shunt. This last pathway is not found in mammals and it is important for the parasites because provides malate, a carbon precursor for anabolic pathways within an environment of nutritional deprivation (Ginger, 2006). Therefore, the enrichment of the glyoxylate shunt in both strains supports the fact that it is essential for T. cruzi.

Interestingly, both strains shared the superpathway of ergosterol biosynthesis, a pathway that generates ergosterol, a characteristic sterol lipid of fungi and kinetoplastids membranes, being critical for T. cruzi. In this regard, huge efforts have been devoted to develop a treatment for Chagas disease using ergosterol biosynthesis inhibitors (Urbina et al., 2002; Shang et al., 2014; Noguera et al., 2018). Our result supports the relevance of this pathway as a good drug target for the parasite since it is enriched in both proteomes.

Regarding the enriched metabolic pathways found uniquely in $\mathrm{Y}$ strain (Fig. 8B), a large number were pathways related with the growth or replication of the parasite, suggesting a higher replication rate of $\mathrm{Y}$ strain respect to VFRA strain. Some of these metabolic pathways were those related with the biosynthesis of adenosine nucleotides and ribonucleotides and the 5-phosphoribose 1-diphosphate (PRPP) indicating the need for an increased nucleotide production. In agreement, other metabolic pathways as cysteine biosynthesis or purine and pyrimidine metabolism were also increased. Interestingly, we found that the most significant metabolic pathway was the mevalonate pathway-I, which generates isopentenyl diphosphate (IPP), being the principal and sole source in many organisms of IPP. This mevalonate pathway leads to the ergosterol biosynthesis-I, another metabolic pathway for the generation of ergosterol, that surprisingly it is enriched only in Y strain. This may indicate a higher dependence on the ergosterol by $\mathrm{Y}$ strain respect to VFRA strain.

Also, in contrast to VFRA, Y strain had enriched the UDP- $N$-acetylglucosamine biosynthesis-I and UDP-glucose biosynthesis, two of the most important metabolic pathways for the glycosylation modification and the production of glycoproteins, which are important for the parasite mediating cellular recognition, host cell adhesion and invasion and immune evasion (Acosta-Serrano et al., 2001; Giorgi and de 
A
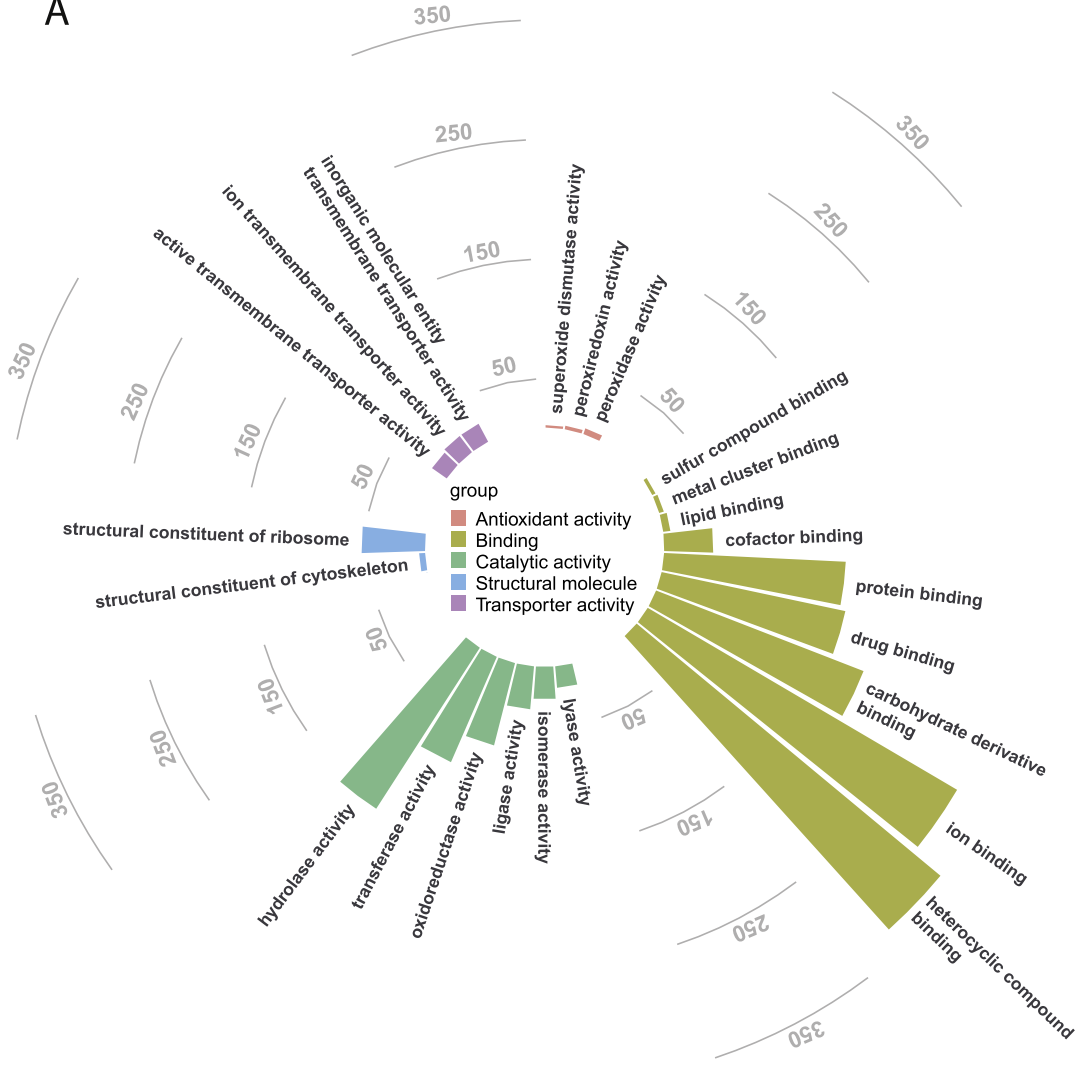

B

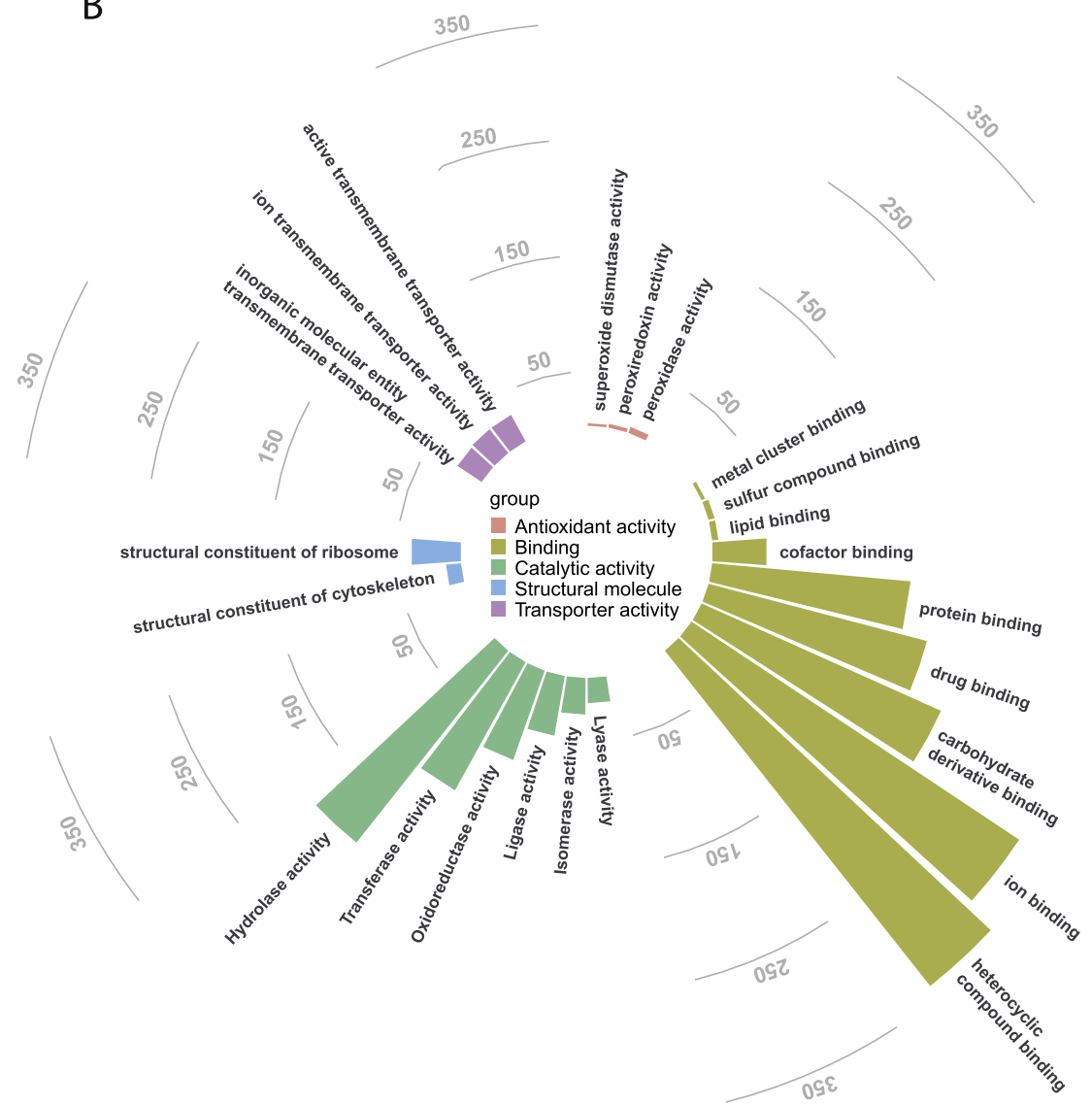

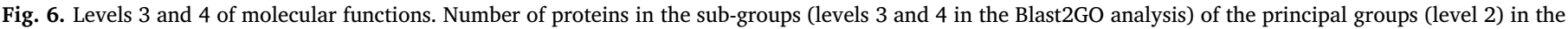
molecular functions ontology. (A) Classification for Y strain. (B) Classification for VFRA strain. 


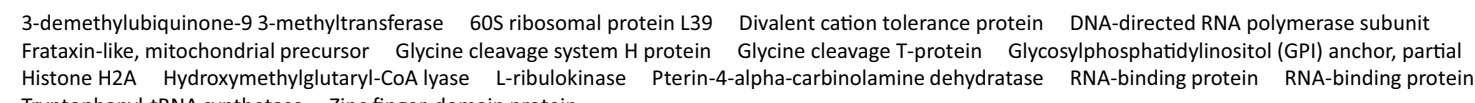
Tryptophanyl-tRNA synthetase Zinc finger-domain protein

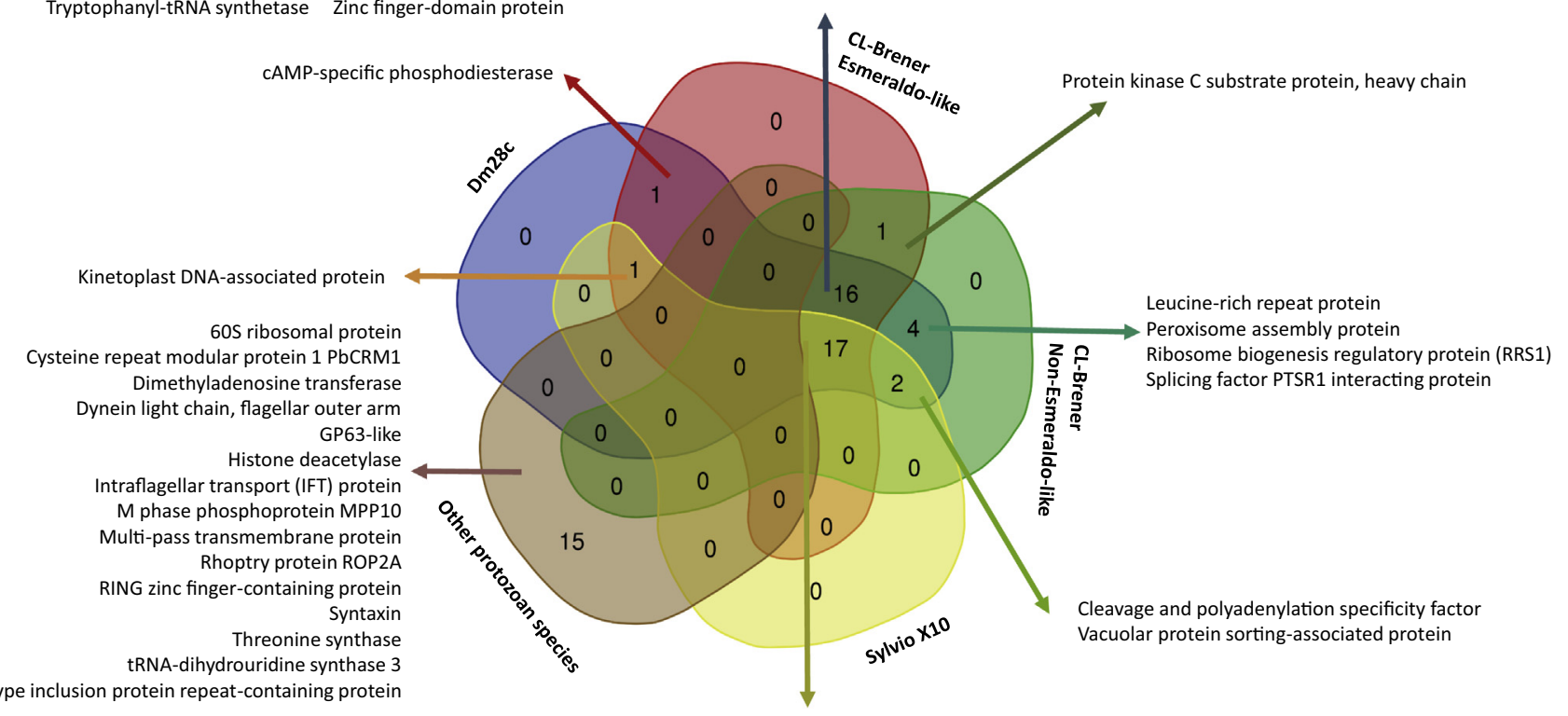

Viral a-type inclusion protein repeat-containing protein

40S ribosomal protein S27 Acetyl-CoA carboxylase Calpain-like cysteine peptidase Cyclin-dependent kinases regulatory subunit DNA ligase I Fatty acid desaturase Glutamine-dependent carbamoyl-phosphate synthetase Kinetoplastid membrane protein KMP-11 Oxidoreductase Phosphatidic acid phosphatase protein Phosphomannomutase-like protein Rab-like GTPase activating protein Ribosomal protein S19 RNA-binding protein rRNA processing protein Small nuclear ribonucleoprotein Transcription activator

B

Acyltransferase ADP-ribosylation factor GTPase activating protein ATP synthase EF-hand protein 5 Expression site-associated protein Farnesyl synthetase Fructosamine kinase Glycerol kinase, glycosomal GPI-anchor transamidase subunit 8 Long-chain-fatty-acid-CoA ligase protein Mitochondrial carrier protein Mu-adaptin 1 Protein transport protein Sec23A Protein-L-isoaspartate O-methyltransferase Pseudouridylate synthase I Riboflavin kinase

Ribosomal P protein AGP2beta-1 Ribosomal protein L29 Small nuclear ribonucleoprotein Sm-E Ubiquitin-activating enzyme Vacuolar ATP synthase

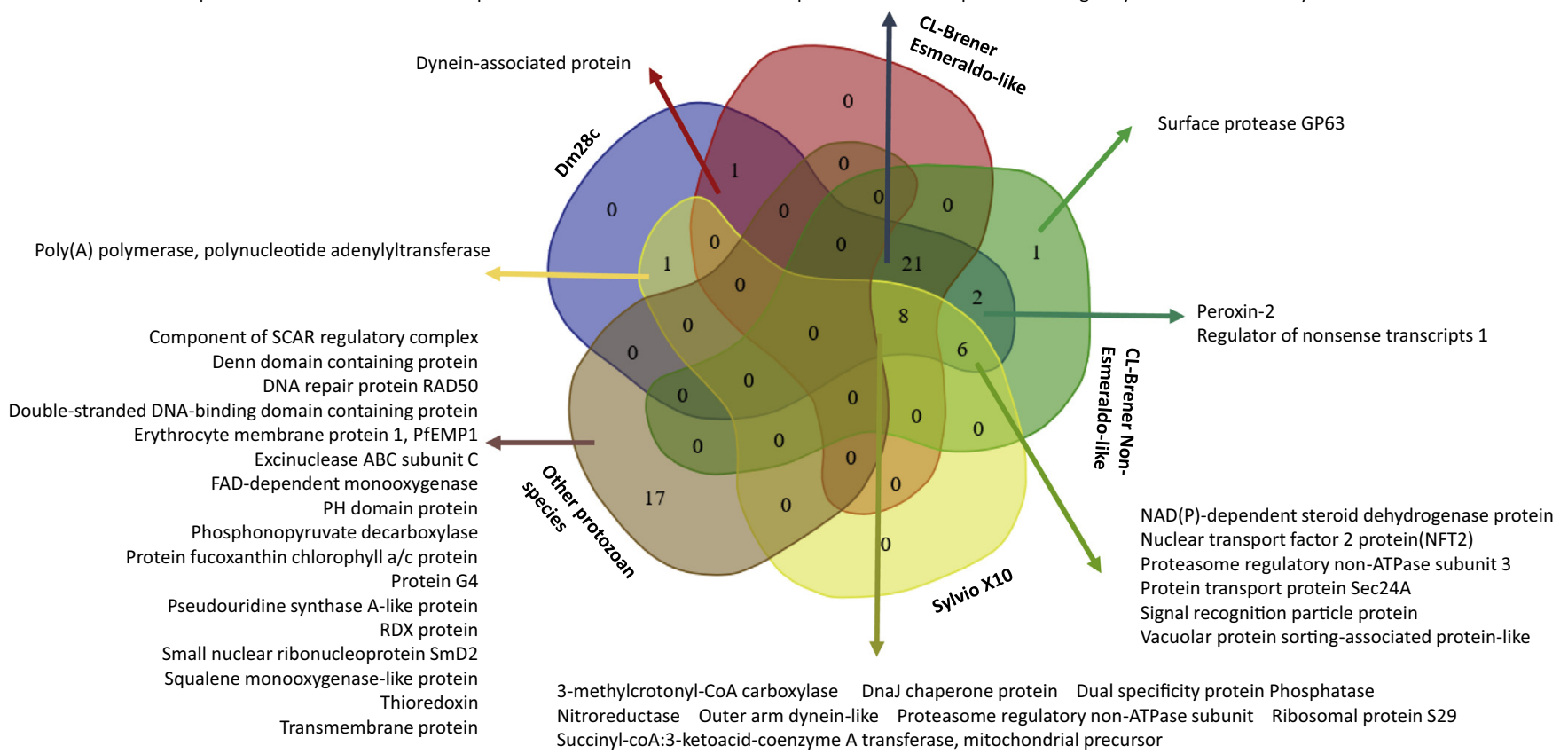

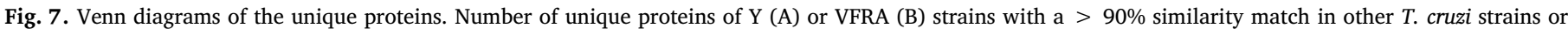

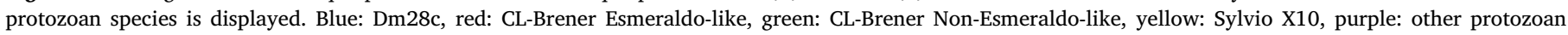

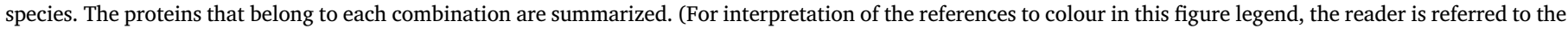
web version of this article.) 
A

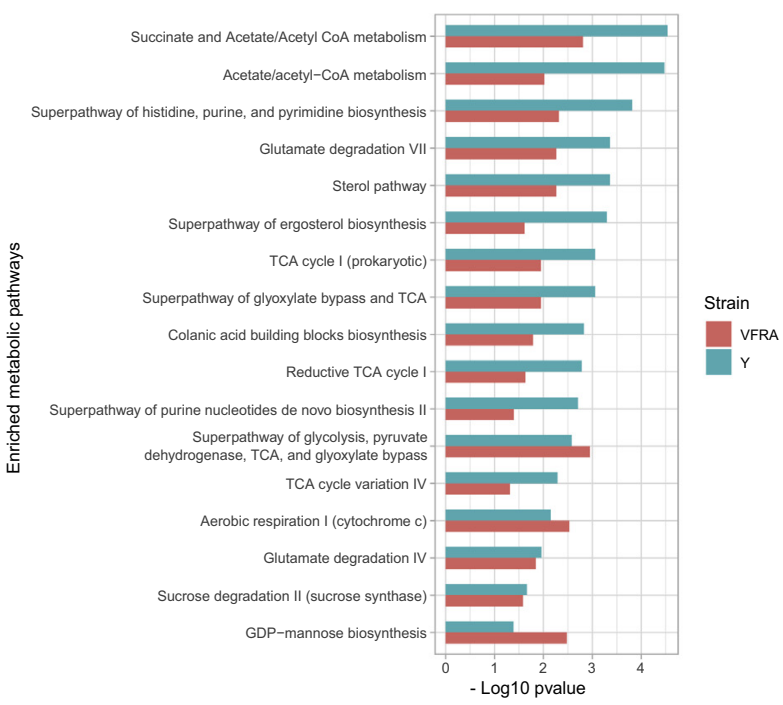

B

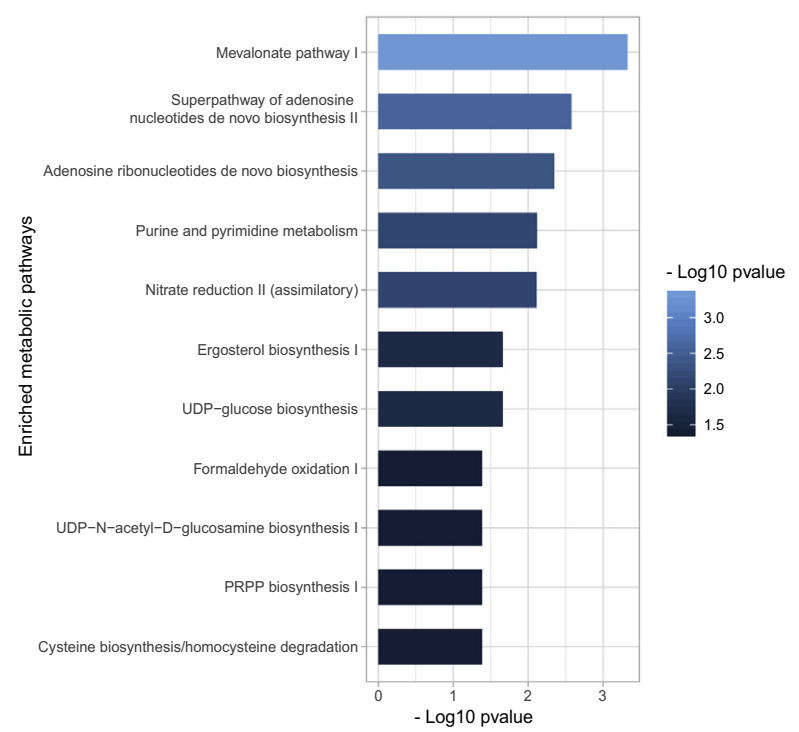

C

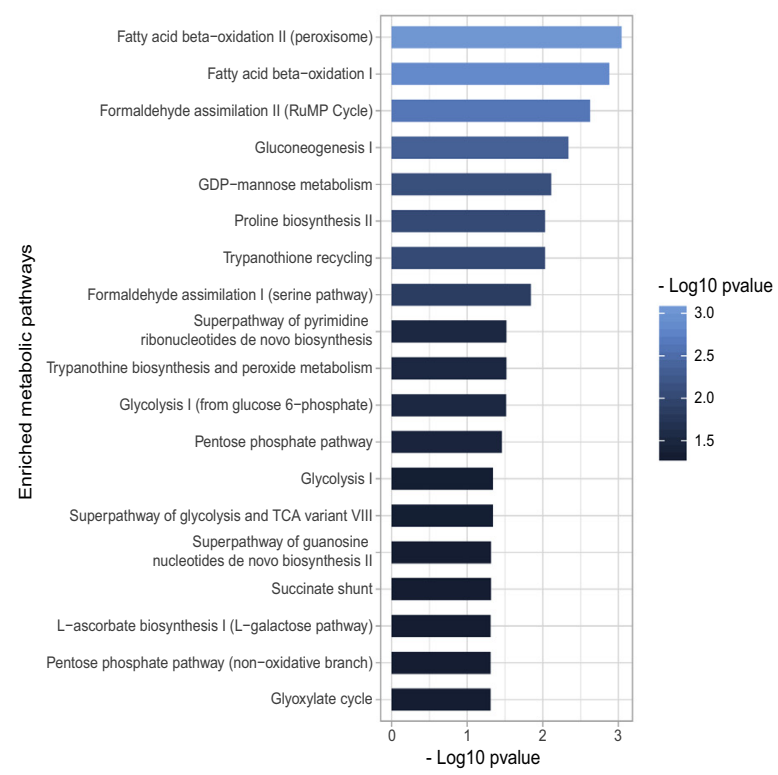

Fig. 8. Enriched metabolic pathways. Fisher's exact test showing the logarithms of the p-values. (A) Shared by both strains, VFRA (red) and Y (blue) strains. (B) Metabolic pathways that were enriched uniquely in $\mathrm{Y}$ strain. (C) Metabolic pathways that were enriched uniquely in VFRA strain. (For interpretation of the references to colour in this figure legend, the reader is referred to the web version of this article.)

Lederkremer, 2011; Alves and Colli, 2007).

In VFRA, we found more unique enriched metabolic pathways (Fig. 8C) including a great enrichment in glycolytic routes. Surprisingly, the gluconeogenesis pathway was also enriched. Curiously, the most significant metabolic pathways were also related with energy production, in particular the fatty acid beta-oxidation, the mitochondrial and the peroxisomal pathways. The principal role of the degradation of fatty acids is the generation of Acetyl-CoA for the TCA cycle and the glyoxylate shunt, that it is critical for the parasite. Our result may suggest that fatty acid beta-oxidation is critical for the cellular catabolism and energy production specifically in VFRA, not being the principal pathway for this purpose in Y strain.

Finally, other interesting enriched metabolic pathways in VFRA strain were those related with the antioxidant defenses. VFRA had enriched the trypanothione recycling and biosynthesis and two branches of the pentose phosphate pathway. The trypanothione is a unique thiol for the elimination of reactive oxygen species (ROS) in trypanosomatids (Ilari et al., 2017), and the pentose phosphate pathway one of the principal sources of NADPH, critical for the antioxidant defenses as electron donor (Kovarova and Barrett, 2016). Moreover, trypanothione is an essential redox molecule in these parasites because the trypasonomatids have no catalases or peroxide hemoproteins to resist oxidative stress. This result suggests that VFRA has better antioxidant responses than Y strain, being more capable to reduce the quantity of ROS in the host cells. The question is why VFRA and not Y displayed this capability and if this is related to different biological behaviors in vivo i.e. the establishment of a chronic infection with VFRA strain. In this regard, ROS production seemed to be beneficial for the infection of macrophages by Y strain (Paiva et al., 2018), and a ROS-derived signal would be required for parasite proliferation (Goes et al., 2016; Paiva et al., 2012). Surprisingly, other strains such as Sylvio X10 would have an opposite behavior (Dhiman and Garg, 2014). On the other hand, the 2 authorized drugs for Chagas disease increase ROS production that may control the parasite. The presence of more or less antioxidant pathways may be related to the different sensitivity to those drugs of different $T$. cruzi strains. Our proteome results, although highly preliminary, since they were performed with only 2 strains, may support that ROS metabolism is important for parasite replication and biological behavior, since a different ROS response seems to occur in VFRA and Y strains that cause different pathogenicity in mice.

In summary, the high parasite loads and remarkable tissue damage produced by mouse infection with Y strain (Rodriguez et al., 2014) can be explained by the conjunction of less antioxidant defenses, that allow more ROS concentration, and the increase in proliferation. On the other hand, VFRA does not cause death in mice, generating something very close to the chronic phase in humans, and had lower proliferation rate in heart acute infection than Y strain (Rodriguez et al., 2014). This behavior would fit with our results of the enrichment in trypanothione metabolism and biosynthesis in VFRA. VFRA would tend to increase these pathways to cope with the great generation of ROS by NOX2 among other enzymes, producing a better control of its own proliferation. This likely allows the establishment of a chronic infection.

\section{Conclusions}

In summary, $\mathrm{Y}$ and VFRA proteomes, although they belong to different DTUs, were very similar at the general biological and gene ontology levels. Nonetheless, some remarkable differences between Y and 
VFRA strains were revealed. They uniquely displayed a $10 \%$ of specific known-function proteins that nonetheless were differently shared by other T. cruzi strains or other protozoan species. Interestingly, VFRA and $\mathrm{Y}$ strains displayed different enriched pathways as antioxidant defenses or replication protein production respectively, which may explain their different pathogenicity in the infected hosts. These facts emphasize the relevance of performing gene ontology and enriched metabolic pathways analysis for this purpose. This type of comparison between strains of the parasite had not been performed before, and it represents a complement for the transcriptomic studies, trying to understand the distinct compositions and host responses that are observed in the infection models of $T$. cruzi.

Supplementary data to this article can be found online at https:// doi.org/10.1016/j.meegid.2019.104041.

\section{Funding}

This work was supported by "Ministerio de Economía y competitividad" SAF2015-63868-R (MINECO/FEDER) and PGC2018-096132-BI00 (MICINN/FEDER) to N.G., SAF2016-75988-R (MINECO/FEDER) to M.F.); "Red de Investigación de Centros de Enfermedades Tropicales, Instituto de Salud Carlos III" (RICET RD12/0018/0004 to M.F.); Comunidad de Madrid (S-2010/BMD-2332 to M.F.); and Institutional grants from "Fundación Ramón Areces" and "Banco de Santander".

\section{Author contributions}

H.-C.A. and C.-H.F. designed and performed the experiments and bioinformatics analysis. F.M. and G.N. designed and supervised the experiments. H.-C.A., C.-H.F., F.M. and G.N. drafted the manuscript. All authors read and approved the final manuscript.

\section{Competing interests}

The authors declare no competing interests.

\section{Acknowledgements}

The authors would like to thank Maria A. Chorro and Maria C. Maza for her excellent technical assistance. We also thank Dr. Ignacio Casal from CIB (CSIC) for his advice in designing the experiment and obtaining of proteomic data.

\section{References}

Acosta-Serrano, A., Almeida, I.C., Freitas-Junior, L.H., Yoshida, N., Schenkman, S., 2001. The mucin-like glycoprotein super-family of Trypanosoma cruzi: structure and biological roles. Mol. Biochem. Parasitol. 114 (2), 143-150.

Alves, M.J., Colli, W., 2007. Trypanosoma cruzi: adhesion to the host cell and intracellular survival. IUBMB Life 59 (4-5), 274-279.

Atwood 3rd, J.A., Weatherly, D.B., Minning, T.A., Bundy, B., Cavola, C., Opperdoes, F.R. Orlando, R., Tarleton, R.L., 2005. The Trypanosoma cruzi proteome. Science 309 (5733), 473-476.

Avila, C.C., Mule, S.N., Rosa-Fernandes, L., Viner, R., Barison, M.J., Costa-Martins, A.G., Oliveira, G.S., Teixeira, M.M.G., Marinho, C.R.F., Silber, A.M., Palmisano, G., 2018. Proteome-wide analysis of Trypanosoma cruzi exponential and stationary growth phases reveals a subcellular compartment-specific regulation. Genes (Basel) 9 (8).

Bayer-Santos, E., Aguilar-Bonavides, C., Rodrigues, S.P., Cordero, E.M., Marques, A.F., Varela-Ramirez, A., Choi, H., Yoshida, N., da Silveira, J.F., Almeida, I.C., 2013. Proteomic analysis of Trypanosoma cruzi secretome: characterization of two populations of extracellular vesicles and soluble proteins. J. Proteome Res. 12 (2), 883-897.

Bermudez, J., Davies, C., Simonazzi, A., Real, J.P., Palma, S., 2016. Current drug therapy and pharmaceutical challenges for Chagas disease. Acta Trop. 156 (1-16).

Bern, C., Montgomery, S.P., Herwaldt, B.L., Rassi Jr., A., Marin-Neto, J.A., Dantas, R.O., Maguire, J.H., Acquatella, H., Morillo, C., Kirchhoff, L.V., Gilman, R.H., Reyes, P.A., Salvatella, R., Moore, A.C., 2007. Evaluation and treatment of chagas disease in the United States: a systematic review. JAMA 298 (18), 2171-2181.

Berna, L., Chiribao, M.L., Greif, G., Rodriguez, M., Alvarez-Valin, F., Robello, C., 2017. Transcriptomic analysis reveals metabolic switches and surface remodeling as key processes for stage transition in Trypanosoma cruzi. PeerJ 5, e3017.

Berna, L., Rodriguez, M., Chiribao, M.L., Parodi-Talice, A., Pita, S., Rijo, G., Alvarez-Valin,
F., Robello, C., 2018. Expanding an expanded genome: long-read sequencing of Trypanosoma cruzi. Microb. Genom. 4 (5).

Brunoro, G.V., Caminha, M.A., Ferreira, A.T., Leprevost Fda, V., Carvalho, P.C., Perales, J., Valente, R.H., Menna-Barreto, R.F., 2015. Reevaluating the Trypanosoma cruzi proteomic map: the shotgun description of bloodstream trypomastigotes. J. Proteome $115,58-65$.

Callejas-Hernandez, F., Rastrojo, A., Poveda, C., Girones, N., Fresno, M., 2018. Genomic assemblies of newly sequenced Trypanosoma cruzi strains reveal new genomic expansion and greater complexity. Sci. Rep. 8 (1), 14631.

Campbell, D.A., Westenberger, S.J., Sturm, N.R., 2004. The determinants of Chagas disease: connecting parasite and host genetics. Curr. Mol. Med. 4 (6), 549-562.

Clayton, J., 2010. Chagas disease 101. Nature 465 (7301), S4-S5.

Conesa, A., Gotz, S., Garcia-Gomez, J.M., Terol, J., Talon, M., Robles, M., 2005. Blast2GO: a universal tool for annotation, visualization and analysis in functional genomics research. Bioinformatics 21 (18), 3674-3676.

Cristobo, I., Larriba, M.J., de los Rios, V., Garcia, F., Munoz, A., Casal, J.I, 2011. Proteomic analysis of 1alpha,25-dihydroxyvitamin D3 action on human colon cancer cells reveals a link to splicing regulation. J. Proteome 75 (2), 384-397.

da Costa, K.M., Valente, R.C., Salustiano, E.J., Gentile, L.B., Freire-de-Lima, L., Mendonca-Previato, L., Previato, J.O., 2018. Functional characterization of ABCC proteins from Trypanosoma cruzi and their involvement with Thiol transport. Front. Microbiol. 9, 205.

de Godoy, L.M., Marchini, F.K., Pavoni, D.P., Rampazzo Rde, C., Probst, C.M., Goldenberg, S., Krieger, M.A., 2012. Quantitative proteomics of Trypanosoma cruzi during metacyclogenesis. Proteomics 12 (17), 2694-2703.

De Souza, W., 2002. Basic cell biology of Trypanosoma cruzi. Curr. Pharm. Des. 8 (4), 269-285.

de Souza, W., de Carvalho, T.M., Barrias, E.S., 2010. Review on Trypanosoma cruzi: host cell interaction. Int. J. Cell Biol. 2010.

Deutsch, E.W., Csordas, A., Sun, Z., Jarnuczak, A., Perez-Riverol, Y., Ternent, T., Campbell, D.S., Bernal-Llinares, M., Okuda, S., Kawano, S., Moritz, R.L., Carver, J.J., Wang, M., Ishihama, Y., Bandeira, N., Hermjakob, H., Vizcaino, J.A., 2017. The ProteomeXchange consortium in 2017: supporting the cultural change in proteomics public data deposition. Nucleic Acids Res. 45 (D1), D1100-D1106.

Dhiman, M., Garg, N.J., 2014. P47phox - / - mice are compromised in expansion and activation of CD8 + T cells and susceptible to Trypanosoma cruzi infection. PLoS Pathog. 10 (12), e1004516.

El-Sayed, N.M., Myler, P.J., Bartholomeu, D.C., Nilsson, D., Aggarwal, G., Tran, A.N., Ghedin, E., Worthey, E.A., Delcher, A.L., Blandin, G., Westenberger, S.J., Caler, E., Cerqueira, G.C., Branche, C., Haas, B., Anupama, A., Arner, E., Aslund, L., Attipoe, P., Bontempi, E., Bringaud, F., Burton, P., Cadag, E., Campbell, D.A., Carrington, M., Crabtree, J., Darban, H., da Silveira, J.F., de Jong, P., Edwards, K., Englund, P.T., Fazelina, G., Feldblyum, T., Ferella, M., Frasch, A.C., Gull, K., Horn, D., Hou, L., Huang, Y., Kindlund, E., Klingbeil, M., Kluge, S., Koo, H., Lacerda, D., Levin, M.J., Lorenzi, H., Louie, T., Machado, C.R., McCulloch, R., McKenna, A., Mizuno, Y., Mottram, J.C., Nelson, S., Ochaya, S., Osoegawa, K., Pai, G., Parsons, M., Pentony, M., Pettersson, U., Pop, M., Ramirez, J.L., Rinta, J., Robertson, L., Salzberg, S.L., Sanchez, D.O., Seyler, A., Sharma, R., Shetty, J., Simpson, A.J., Sisk, E., Tammi, M.T., Tarleton, R., Teixeira, S., Van Aken, S., Vogt, C., Ward, P.N., Wickstead, B., Wortman, J., White, O., Fraser, C.M., Stuart, K.D., Andersson, B., 2005. The genome sequence of Trypanosoma cruzi, etiologic agent of Chagas disease. Science 309 (5733), 409-415.

Franzen, O., Ochaya, S., Sherwood, E., Lewis, M.D., Llewellyn, M.S., Miles, M.A., Andersson, B., 2011. Shotgun sequencing analysis of Trypanosoma cruzi I Sylvio X10/1 and comparison with T. cruzi VI CL Brener. PLoS Negl. Trop. Dis. 5 (3), e984.

Gil-Jaramillo, N., Motta, F.N., Favali, C.B., Bastos, I.M., Santana, J.M., 2016. Dendritic cells: a double-edged sword in immune responses during Chagas disease. Front. Microbiol. 7, 1076

Ginger, M.L., 2006. Niche metabolism in parasitic protozoa. Philos. Trans. R. Soc. Lond. Ser. B Biol. Sci. 361 (1465), 101-118.

Giorgi, M.E., de Lederkremer, R.M., 2011. Trans-sialidase and mucins of Trypanosoma cruzi: an important interplay for the parasite. Carbohydr. Res. 346 (12), 1389-1393.

Goes, G.R., Rocha, P.S., Diniz, A.R., Aguiar, P.H., Machado, C.R., Vieira, L.Q., 2016. Trypanosoma cruzi needs a signal provided by reactive oxygen species to infect macrophages. PLoS Negl. Trop. Dis. 10 (4), e0004555.

Grisard, F.C., Teixeira, S.M., de Almeida, L.G., Stoco, P.H., Gerber, A.L., Talavera-Lopez, C., Lima, O.C., Andersson, B., de Vasconcelos, A.T., 2014. Trypanosoma cruzi clone Dm28c draft genome sequence. Genome Announc. 2 (1).

Gupta, I., Aggarwal, S., Singh, K., Yadav, A., Khan, S., 2018. Ubiquitin proteasome pathway proteins as potential drug targets in parasite Trypanosoma cruzi. Sci. Rep. 8 (1), 8399.

Hannaert, V., Saavedra, E., Duffieux, F., Szikora, J.P., Rigden, D.J., Michels, P.A., Opperdoes, F.R., 2003. Plant-like traits associated with metabolism of Trypanosoma parasites. Proc. Natl. Acad. Sci. U. S. A. 100 (3), 1067-1071.

Ilari, A., Fiorillo, A., Genovese, I., Colotti, G., 2017. Polyamine-trypanothione pathway: an update. Future Med. Chem. 9 (1), 61-77.

Kall, L., Canterbury, J.D., Weston, J., Noble, W.S., MacCoss, M.J., 2007. Semi-supervised learning for peptide identification from shotgun proteomics datasets. Nat. Methods 4 (11), 923-925.

Kovarova, J., Barrett, M.P., 2016. The pentose phosphate pathway in parasitic Trypanosomatids. Trends Parasitol. 32 (8), 622-634.

Lima, L., Espinosa-Alvarez, O., Ortiz, P.A., Trejo-Varon, J.A., Carranza, J.C., Pinto, C.M., Serrano, M.G., Buck, G.A., Camargo, E.P., Teixeira, M.M., 2015. Genetic diversity of Trypanosoma cruzi in bats, and multilocus phylogenetic and phylogeographical analyses supporting Tcbat as an independent DTU (discrete typing unit). Acta Trop. 151, 166-177.

Manoel-Caetano Fda, S., Silva, A.E., 2007. Implications of genetic variability of 
Trypanosoma cruzi for the pathogenesis of Chagas disease. Cad. Saude Publica 23 (10), 2263-2274.

Marcili, A., Lima, L., Cavazzana, M., Junqueira, A.C., Veludo, H.H., Maia Da Silva, F., Campaner, M., Paiva, F., Nunes, V.L., Teixeira, M.M., 2009. A new genotype of Trypanosoma cruzi associated with bats evidenced by phylogenetic analyses using SSU rDNA, cytochrome b and histone H2B genes and genotyping based on ITS1 rDNA. Parasitology 136 (6), 641-655.

Mulangi, V., Chibucos, M.C., Phuntumart, V., Morris, P.F., 2012. Kinetic and phylogenetic analysis of plant polyamine uptake transporters. Planta 236 (4), 1261-1273.

Muller Kratz, J., Garcia Bournissen, F., Forsyth, C.J., Sosa-Estani, S., 2018. Clinical and pharmacological profile of benznidazole for treatment of Chagas disease. Expert. Rev. Clin. Pharmacol. 11 (10), 943-957.

Noguera, G.J., Fabian, L.E., Lombardo, E., Finkielsztein, L.M., 2018. Studies of 4-arylthiazolylhydrazones derived from 1-indanones as Trypanosoma cruzi squalene epoxidase inhibitors by molecular simulations. Org. Biomol. Chem. 16 (44), $8525-8536$.

Paiva, C.N., Feijo, D.F., Dutra, F.F., Carneiro, V.C., Freitas, G.B., Alves, L.S., Mesquita, J., Fortes, G.B., Figueiredo, R.T., Souza, H.S., Fantappie, M.R., Lannes-Vieira, J., Bozza, M.T., 2012. Oxidative stress fuels Trypanosoma cruzi infection in mice. J. Clin. Invest. 122 (7), 2531-2542.

Paiva, C.N., Medei, E., Bozza, M.T., 2018. ROS and Trypanosoma cruzi: fuel to infection, poison to the heart. PLoS Pathog. 14 (4), e1006928.

Perez-Riverol, Y., Csordas, A., Bai, J., Bernal-Llinares, M., Hewapathirana, S., Kundu, D.J., Inuganti, A., Griss, J., Mayer, G., Eisenacher, M., Perez, E., Uszkoreit, J., Pfeuffer, J., Sachsenberg, T., Yilmaz, S., Tiwary, S., Cox, J., Audain, E., Walzer, M., Jarnuczak, A.F., Ternent, T., Brazma, A., Vizcaino, J.A., 2019. The PRIDE database and related tools and resources in 2019: improving support for quantification data. Nucleic Acids Res. 47 (D1), D442-D450.

Queiroz, R.M., Charneau, S., Motta, F.N., Santana, J.M., Roepstorff, P., Ricart, C.A., 2013. Comprehensive proteomic analysis of Trypanosoma cruzi epimastigote cell surface proteins by two complementary methods. J. Proteome Res. 12 (7), 3255-3263.

Rassi Jr., A., Rassi, A., Marcondes de Rezende, J., 2012. American trypanosomiasis (Chagas disease). Infect. Dis. Clin. N. Am. 26 (2), 275-291.

Reis-Cunha, J.L., Rodrigues-Luiz, G.F., Valdivia, H.O., Baptista, R.P., Mendes, T.A., de Morais, G.L., Guedes, R., Macedo, A.M., Bern, C., Gilman, R.H., Lopez, C.T., Andersson, B., Vasconcelos, A.T., Bartholomeu, D.C., 2015. Chromosomal copy number variation reveals differential levels of genomic plasticity in distinct Trypanosoma cruzi strains. BMC Genomics 16, 499.

Ribeiro, K.S., Vasconcellos, C.I., Soares, R.P., Mendes, M.T., Ellis, C.C., Aguilera-Flores, M., de Almeida, I.C., Schenkman, S., Iwai, L.K., Torrecilhas, A.C., 2018. Proteomic analysis reveals different composition of extracellular vesicles released by two Trypanosoma cruzi strains associated with their distinct interaction with host cells. J. Extracell. Vesicles 7 (1), 1463779.
Rodrigues, J.C., Godinho, J.L., de Souza, W., 2014. Biology of human pathogenic trypanosomatids: epidemiology, lifecycle and ultrastructure. Subcell. Biochem. 74, 1-42.

Rodriguez, H.O., Guerrero, N.A., Fortes, A., Santi-Rocca, J., Girones, N., Fresno, M., 2014. Trypanosoma cruzi strains cause different myocarditis patterns in infected mice. Acta Trop. 139, 57-66.

Sales Junior, P.A., Molina, I., Fonseca Murta, S.M., Sanchez-Montalva, A., Salvador, F., Correa-Oliveira, R., Carneiro, C.M., 2017. Experimental and clinical treatment of Chagas disease: a review. Am. J. Trop. Med. Hyg. 97 (5), 1289-1303.

Schmunis, G.A., Yadon, Z.E., 2010. Chagas disease: a Latin American health problem becoming a world health problem. Acta Trop. 115 (1-2), 14-21.

Shang, N., Li, Q., Ko, T.P., Chan, H.C., Li, J., Zheng, Y., Huang, C.H., Ren, F., Chen, C.C., Zhu, Z., Galizzi, M., Li, Z.H., Rodrigues-Poveda, C.A., Gonzalez-Pacanowska, D., Veiga-Santos, P., de Carvalho, T.M., de Souza, W., Urbina, J.A., Wang, A.H., Docampo, R., Li, K., Liu, Y.L., Oldfield, E., Guo, R.T., 2014. Squalene synthase as a target for Chagas disease therapeutics. PLoS Pathog. 10 (5), e1004114.

Teich, R., Zauner, S., Baurain, D., Brinkmann, H., Petersen, J., 2007. Origin and distribution of Calvin cycle fructose and sedoheptulose bisphosphatases in plantae and complex algae: a single secondary origin of complex red plastids and subsequent propagation via tertiary endosymbioses. Protist 158 (3), 263-276.

Teixeira, A.R., Nascimento, R.J., Sturm, N.R., 2006. Evolution and pathology in chagas disease-a review. Mem. Inst. Oswaldo Cruz 101 (5), 463-491.

Urbina, J.A., Concepcion, J.L., Rangel, S., Visbal, G., Lira, R., 2002. Squalene synthase as a chemotherapeutic target in Trypanosoma cruzi and Leishmania mexicana. Mol. Biochem. Parasitol. 125 (1-2), 35-45.

World Health Organization Chagas disease (American trypanosomiasis), 2019. https:// www.who.int/chagas/en/ (accessed 20 March).

Zingales, B., 2018. Trypanosoma cruzi genetic diversity: something new for something known about Chagas disease manifestations, serodiagnosis and drug sensitivity. Acta Trop. 184, 38-52.

Zingales, B., Andrade, S.G., Briones, M.R., Campbell, D.A., Chiari, E., Fernandes, O., Guhl, F., Lages-Silva, E., Macedo, A.M., Machado, C.R., Miles, M.A., Romanha, A.J., Sturm, N.R., Tibayrenc, M., Schijman, A.G., Second Satellite, M., 2009. A new consensus for Trypanosoma cruzi intraspecific nomenclature: second revision meeting recommends TcI to TcVI. Mem. Inst. Oswaldo Cruz 104 (7), 1051-1054.

Zingales, B., Miles, M.A., Campbell, D.A., Tibayrenc, M., Macedo, A.M., Teixeira, M.M., Schijman, A.G., Llewellyn, M.S., Lages-Silva, E., Machado, C.R., Andrade, S.G., Sturm, N.R., 2012. The revised Trypanosoma cruzi subspecific nomenclature: rationale, epidemiological relevance and research applications. Infect. Genet. Evol. 12 (2), 240-253.

Zingales, B., Araujo, R.G., Moreno, M., Franco, J., Aguiar, P.H., Nunes, S.L., Silva, M.N., Ienne, S., Machado, C.R., Brandao, A., 2015. A novel ABCG-like transporter of Trypanosoma cruzi is involved in natural resistance to benznidazole. Mem. Inst. Oswaldo Cruz 110 (3), 433-444. 